\title{
La Constitución y las Relaciones Internacionales
}

Diego Cordovez

\author{
Siempre es conveniente que juristas conocedores del derecho \\ internacional intervengan en la redacción de las disposiciones \\ que regulan los temas de política exterior, y es evidente que la \\ Asamblea Constituyente no procedió en esa forma.
}

Siguiendo el buen ejemplo de varios autores de otros artículos publicados en Iuris Dictio, este ensayo contiene fundamentalmente un esbozo - se podría decir "brochazos" - de un tema muy amplio, escrito con el propósito de estimular el interés de los alumnos del Colegio de Jurisprudencia en los asuntos internacionales.

No se corre el riesgo de abrir una polémica - como las que suscita la sola mención de la globalización - si se afirma que vivimos en un mundo cada día más interdependiente. Se podría decir que hemos iniciado el camino hacia la cohabitación en esa "aldea planetaria" que con frecuencia invoca Kofi Annan, el secretario general de las Naciones Unidas. Ese proceso involucra una intensificación de la acción internacional de los Estados, lo cual, a su vez, requiere la adopción, y periódica actualización, de disposiciones del ordenamiento jurídico interno relativas a la convivencia internacional.

Una buena parte de las enmiendas constitucionales que diversos Estados introducen actualmente se inscriben en el afán de los gobiernos y los parlamentos de buscar una más amplia y eficiente participación en actividades internacionales, sean de carácter bilateral o multilateral. Los organismos internacionales promueven constantemente la adopción de normas que regulan una gama cada vez más amplia de temas y asuntos. La interdependencia se construye mediante incesantes negociaciones entre Estados y la celebración de acuerdos sobre una creciente variedad de materias.

Nuestra actual Constitución, que entró en vigor hace solo dos años, introdujo algunos cambios en el régimen jurídico relativo a las relaciones internacionales del Ecuador, pero adolece de vacíos y errores, principalmente de carácter conceptual, que será necesario rectificar en el futuro.

En su Artículo $1^{\circ}$, la Constitución identifica al Ecuador como "un estado social de derecho, soberano, unitario, independiente, democrático, pluricultural y multiétnico" y describe su Gobierno como "republicano, presidencial, electivo, representativo, responsable, alternativo, participativo y de administración descentralizada". Aunque presu- miblemente a muchos ecuatorianos les puede parecer que estas afirmaciones constituyen más una expresión de propósitos, o de ilusiones, que una descripción de la realidad, para los otros miembros de la comunidad internacional esas son, formalmente, las condiciones institucionales y jurídicas que la nación ecuatoriana ha adoptado al constituirse y funcionar como Estado. El Estado es el sujeto primordial del derecho internacional $y$, como tal, puede invocar derechos y asumir obligaciones, que constituyen los principales parámetros de la convivencia internacional. ${ }^{\prime}$

De hecho, la Constitución, en el artículo $4^{\circ}$, establece las normas y principios generales de las relaciones del Estado ecuatoriano con la comunidad internacional $y$, en ese contexto, proclama la paz, la cooperación como sistema de convivencia y la igualdad jurídica de los Estados. Los principios de derecho internacional que se enumeran en esa disposición son los que han regulado la conducta internacional del Ecuador desde que fueron enunciados y aceptados como tales por la comunidad internacional - la prohibición del uso o la amenaza de la fuerza, la solución pacífica de las controversias, el desconocimiento del despojo bélico como fuente de derecho, la autodeterminación de los pueblos- y la Constitución también afirma que el Ecuador propugna la integración y rechaza toda forma de colonialismo, discriminación y segregación. El Ecuador, de acuerdo con la misma disposición, "podrá formar asociaciones con uno o más Estados para la promoción y defensa de los intereses nacionales y comunitarios."

La Constitución de 1998 consagra una vez más el principio de que es el Presidente de la República quien tiene la función privativa de conducir las relaciones internacionales del Ecuador. El artículo 171, párrafo 12, prescribe que una de las atribuciones y deberes del Presidente es: "Definir la política exterior, dirigir las relaciones internacionales, celebrar y ratificar los tratados y convenios internacionales, previa aprobación del Congreso Nacional, cuando la Constitución lo exija". El párrafo 15 del mismo artículo dispone que el Presidente de la República debe "asumir la dirección política de la guerra". 
La Constitución actual merece en ese contexto unas breves observaciones. Al utilizar el término "definir", en vez de "determinar", que se había adoptado en la Constitución anterior, se ha buscado una mayor precisión, probablemente para evitar eventuales conflictos de jurisdicción. De acuerdo con el Diccionario de la Lengua Española, definir es "fijar con claridad, exactitud y precisión..." y engloba el concepto de "determinar" porque también significa "decidir, determinar, resolver una cosa dudosa". Pero lamentablemente, en la segunda parte de esa misma disposición, la Constitución actual incurre en un error de concepto, derivado, seguramente, de una mala redacción.

En efecto, el texto sugiere que, al menos en ciertos casos, el Presidente requiere de la aprobación del Congreso para "celebrar" tratados. Justamente porque el Presidente tiene la facultad de definir la política exterior, tiene la prerrogativa de celebrar tratados si, como es de presumirse, el término "celebrar" involucra la negociación y la suscripción de los instrumentos correspondientes. Es evidente que la Constitución no tiene la intención de restringir la facultad del Presidente de celebrar tratados; el artículo 161 solamente enumera los tratados que el Congreso debe aprobar o improbar una vez que el Presidente de la República los ha celebrado. Se trata, entonces, fundamentalmente de un caso de redacción equívoca.

Debe también observarse que la Constitución usa la expresión "tratados y convenciones" repetidamente, lo cual no se concilia con la doctrina ni con los preceptos de la Convenciones de La Habana de 1928 y de Viena de 1969 sobre derecho de los tratados, que emplean el término "tratado" como comprensivo de todos los acuerdos internacionales. Tratado y convención constituyen el mismo objeto jurídico.

Al reafirmar que el Presidente de la República dirige las relaciones internacionales, nuestra actual Constitución adopta un enfoque que, con pequeñas diferencias, constituye la regla general en los regímenes presidenciales. En el sistema parlamentario se producen dificultades en ese contexto cuando la constitución - la de Francia, por ejemplo- dispone explícita o implícitamente que tanto el jefe del Estado como el jefe del Gobierno tienen facultades relacionadas con la política exterior. (Esa es la razón por la cual Francia es el único miembro de la Unión Europea que siempre está representado conjuntamente por el presidente y el primer ministro en las reuniones "cumbre".) Demás está agregar que, excepto en los casos en que el Presidente de la República lo solicite expresamente, cualquier resolución del Congreso sobre materias de política exterior, salvo aquellas expresamente prescritas, sería, en estricto derecho, inconstitucional.

Nuestra actual Constitución, además, confirmó las reformas que se habían introducido en la Carta Política anterior para eliminar la autorización formal para salir del país que el Presidente debía obtener cada vez que abandonaba el territorio nacional y la "entrega del mando" al vicepresidente, que era obligatoria en tales casos.

En una época de aviones a reacción, celulares y faxes, y de aviones con teléfonos y faxes, dichas disposiciones eran arcaicas y absurdas, y se contraponían legal y prácticamente a las responsabilidades que ejerce el Presidente, quien debe tener en todo momento, real y aparentemente, la competencia legal para declarar la voluntad del Estado ecuatoriano respecto de sus relaciones con otros Estados. Ahora que la diplomacia personal es tan intensa se podría aducir que, antes de que se adoptaran esas reformas, nuestro presidente no tenía, en las circunstancias jurídicas en que viajaba al exterior, la atribución de suscribir acuerdos internacionales, que es, frecuentemente, el objetivo de los desplazamientos del jefe del Estado. También se podría sostener que, al entregar sus poderes constitucionales al vicepresidente, el presidente, desde el momento en que abandonaba el territorio nacional, no estaba amparado por las inmunidades, ni gozaba de los privilegios, que por su alta investidura le corresponden de acuerdo con el derecho internacional.

El Artículo 170 de la Constitución actual dispone que el Presidente de la República, durante su mandato y hasta un año después de haber cesado en sus funciones, deberá comunicar al Congreso, con antelación, "su decisión" de ausentarse del país. "No se considerará falta temporal la ausencia del país por asuntos inherentes a sus funciones", dice el artículo 169 que, en caso de enfermedad u otra circunstancia que le impida transitoriamente ejercer su función, o licencia concedida por el Congreso, prescribe el reemplazo del presidente por el vicepresidente o el ministro de Estado que designe el presidente. La misma disposición autoriza al presidente a "delegar determinadas atribuciones" al vicepresidente cuando se ausenta del país por obligaciones propias de su cargo.

El jefe del Estado ejerce sus atribuciones relacionadas con la política exterior mediante el servicio exterior, que dirige el canciller de la República. El canciller es, en la práctica, el ejecutor de la política exterior del Estado que el presidente de la República define, aunque, como ya se ha dicho, es habitual desde hace algunos años que los jefes del Estado y de Gobierno conduzcan personalmente negociaciones y consultas internacionales, y concluyan todo tipo de acuerdos con sus pares de otros Estados. Solamente el jefe del Estado y el ministro de Relaciones Exteriores tienen autoridad para hablar por y comprometer al Estado internacionalmente. (Cuando se encarga a otro funcionario una misión o gestión de política exterior debe recibir poderes especiales firmados por el presidente y el canciller.) $\mathrm{La}$ Cancillería coordina y supervisa el trabajo de las representaciones en el exterior. La Ley Orgánica del Servicio Exterior, que regula el funcionamiento del servicio exterior, fue expedida en 1964 por un gobierno militar, y debería reemplazarse por una nueva legislación para promover el funcionamiento de la Cancillería y de nuestras representaciones en el exterior de acuerdo con las normas y prácticas de la diplomacia moderna y los objetivos actuales de nuestra política exterior.

La aprobación de tratados es la única función del Congreso en el ámbito de la política exterior. Las disposiciones de la actual Constitución en ese contexto son las que normalmente se aplican en un régimen presidencial. El jefe del Estado tiene a su cargo la negociación y conclusión (o celebración) de tratados, el Congreso tiene la atribución de aprobar o rechazar aquellos que la Constitución enumera y, en los casos previstos en los tratados de que se trate, el Presidente entonces procede a la ratificación y al intercambio, o "depósito" en el caso de tratados multilaterales, de los instrumentos correspondientes. Nuestra Constitución, al igual que muchas otras, prescribe taxativamente los trata- 
dos que requieren aprobación parlamentaria. Otras constituciones adoptan un enfoque conceptual y definen más bien los diversos tipos de tratado que deben someterse al Congreso.

En el Congreso de los Estados Unidos y, con variaciones, en otros parlamentos, se ha adoptado recientementé, debido a la creciente complejidad de las relaciones internacionales, un procedimiento, llamado "fast track" (algo así como "andarivel rápido") mediante el cual, con respecto a tratados que requieren de aprobación parlamentaria, el Congreso autoriza al ejecutivo a participar, por ejemplo, en una negociación comercial y se compromete al mismo tiempo a aprobar o rechazar el tratado resultante de esas negociaciones sin introducir enmiendas durante la consideración del acuerdo que hubiere celebrado el gobierno.

Nuestra Constitución no contempla formalmente la adhesión del Ecuador a un tratado. La adhesión, cada vez más frecuente en relación con tratados multilaterales, es un acto jurídico por el cual un Estado se constituye en parte de un tratado del cual no es signatario mediante una declaración formal hecha en virtud de una disposición del tratado que la permita. Los tratados que autorizan la adhesión de Estados que no los han suscrito se denominan "tratados multilaterales abiertos". En ausencia de una disposición específica sobre adhesión, en la práctica se somete el tratado de que se trate al proceso usual, como si el Ecuador fuera uno de los signatarios originales del instrumento sometido a aprobación del Congreso.

En su Artículo 161 la Constitución enumera los tratados que requieren consideración legislativa. Estos son: 1. Los que se refieren a materia territorial o de límites; 2 . Los que establezcan alianzas políticas o militares; 3 . Los que comprometan al país en acuerdos de integración; 4. Los que atribuyan a un organismo internacional o supranacional el ejercicio de competencias derivadas de la Constitución o la ley; 5 . Los que se refieren a los derechos y deberes fundamentales de las personas y a los derechos colectivos; $y, 6$. Los que contengan el compromiso de expedir, modificar o derogar alguna ley. El trámite de aprobación se debe cumplir en un solo debate y con el voto conforme de la mayoría de los miembros de Congreso.

Previamente, el Congreso debe solicitar un dictamen del Tribunal Constitucional respecto a la conformidad del tratado sometido a su aprobación con la Constitución. Cuando un tratado exige una reforma constitucional, la aprobación no podrá efectuarse "sin que antes se haya expedido dicha reforma." (Artículo 162) Nuestra Constitución también contiene una disposición, acorde con el derecho internacional, que prescribe que las normas contenidas en los tratados, una vez promulgadas en el Registro Oficial, "formarán parte del ordenamiento jurídico de la República y prevalecerán sobre leyes y otras normas de menor jerarquía". (Artículo 163). El texto de la actual Constitución, que utiliza los términos "formarán parte", prescribe la incorporación automática de la disposición o tratado de que se trate - sin más trámite, como se requería anteriormente- en el momento de la promulgación. Sobre la significación práctica de esta disposición probablemente se podría escribir un libro entero, pero basta señalar aquí que varios organismos internacionales consideran que el Ecuador no incorpora, real y prácticamente, las normas que contienen tratados de los que es parte a la legislación nacional —en el sentido de que se apliquen en la administración de justicia o en el campo laboral- no obstante haberse cumplido todos los requisitos de suscripción, aprobación y promulgación.

En la mayoría de los Gobiernos, tanto en países desarrollados como en desarrollo, hay una marcada reticencia a someter tratados a la aprobación parlamentaria. Por lo tanto, en las negociaciones que anteceden la celebración de un tratado se tienen muy en cuenta los términos utilizados en los textos constitucionales a fin de evadir la presentación del tratado al Congreso aduciendo su exclusión de la enumeración taxativa que contiene la constitución. (Esta es, en efecto, una de las principales razones por las cuales en algunos países se ha adoptado el enfoque "conceptual", que requiere la aprobación de ciertos tipos de tratados, lo cual complica la labor de los negociadores que, tratándose de una constitución que enumera los tratados que deben recibir aprobación legislativa, pueden manipular el lenguage de los textos correspondientes.) La razón de esta reticencia es muy simple: el proceso de aprobación abre la puerta a todo tipo de "intromisiones" del parlamento en materias de política exterior, introduce observaciones que pueden afectar las relaciones del país con la otra parte o partes de un tratado y hasta puede entrabar y hasta paralizar la ejecución de un tratado.

No obstante las precauciones que los gobiemos adoptan durante las negociaciones de un tratado para evitar su consideración por los parlamentos, la disposición constitucional que estipula la intervención parlamentaria en su tramitación da lugar, en la mayoría de los países, a encendidas disputas y controversias de interpretación. (En los Estados Unidos, por ejemplo, se produce una disputa entre los poderes ejecutivo y legislativo cada vez que el presidente ordena una intervención de las fuerzas armadas en un conflicto en el exterior.) En el Ecuador, desde que la actual Constitución entró en vigor han sido motivo de polémica y de interpretaciones contradictorias dos instrumentos internacionales de alguna importancia.

En el caso del Tratado de Comercio y Navegación entre los Gobiernos de la República del Ecuador y de la República del Perú, que formó parte del acuerdo de Brasilia y que fue sometido a aprobación parlamentaria muy poco después de la entrada en vigor de la actual Constitución, el Congreso resolvió, de acuerdo con un informe de mayoría de la Comisión Especializada de Asuntos Internacionales, que ese Tratado no requería de aprobación legislativa por pertenecer "a una especie de convenios internacionales conocidos en el Derecho Internacional Público, en su prácti$\mathrm{ca}$, su doctrina y su jurisprudencia como 'Acuerdos Ejecutivos' (Executive Agreements), 'Acuerdos de Ejecución' o 'Acuerdos de Forma Simplificada'." (Ese Tratado, en efecto, se había suscrito en cumplimiento de una disposición especifica del Protocolo de Río de Janeiro). Pero en un informe de minoría se sostenía que el Tratado debía ser considerado por el Congreso porque se refiere a materia territorial o de límites (numeral $1^{\circ}$ del artículo 161) y también, de acuerdo con el numeral 5 del mismo artículo, porque se refiere a los derechos y deberes fundamentales de las personas y a los derechos colectivos".

El segundo tratado que ha dado lugar a controversia es el Acuerdo de Cooperación entre el Gobierno de la República del Ecuador y el Gobierno de los Estados Unidos de 
América concerniente al acceso y uso de los Estados Unidos de América de las instalaciones de la Base de la Fuerza Aérea Ecuatoriana en Manta para actividades aéreas antinarcóticos, suscrito el 12 de noviembre de 1999. El Informe a la Nación correspondiente al periodo 1998-1999, sometido conjuntamente al Congreso por los cancilleres José Ayala y Benjamín Ortiz, señala que dicho acuerdo fue previamente conocido y aprobado por la Comisión de Asuntos Internacionales del Congreso. ${ }^{3}$ Pero cuando la conveniencia política y militar del Acuerdo, y la relación del mismo con el Plan Colombia, surgió como un tema polémico de discusión pública, varios parlamentarios, analistas y expertos en derecho internacional, afirmaron que la Comisión de Asuntos Internacionales carecía de la facultad de aprobar el acuerdo - fundamentalmente porque las comisiones tienen atribuciones exclusivamente de recomendación al Congreso- y sostenían, además, que el Congreso debió considerar el Acuerdo de conformidad con el numeral 2 del artículo 161 de la Constitución, según el cual requieren aprobación parlamentaria los tratados que "establezcan alianzas políticas o militares".

Al margen de estas consideraciones, en el Ecuador el proceso de aprobación parlamentaria es excesivamente lento, lo cual involucra dificultades para el Presidente y la Cancillería en sus relaciones con otros Estados y con organizaciones internacionales, y afecta la credibilidad del país y sus instituciones. Además, con frecuencia torna intrascendentes a los debates y resoluciones legislativas porque -en el caso de tratados multilaterales, por ejemplocuando el Congreso ecuatoriano aprueba con excesivo retardo un tratado, éste puede haber entrado en vigor por haber recibido el número requerido de ratificaciones de otros Estados.

Veamos un ejemplo concreto. El Protocolo de Reformas a la Carta de la Organización de Estados Americanos - también llamado Protocolo de Cartagena de Indias - fue aprobado el 4 de diciembre de 1985 y suscrito al día siguiente. Durante el Gobierno del presidente León Febres Cordero, el canciller Rafael García Velasco, mediante una comunicación al presidente del Congreso Nacional, Andrés Vallejo, fechada el 27 de mayo de 1987, sometió el Protocolo de Cartagena a la consideración parlamentaria. Recién el 13 de febrero de 1990, casi tres años después, el Congreso aprobó el Protocolo, que el presidente Rodrigo Borja ratificó el 27 de abril de 1990. El 22 de mayo de ese mismo año, nuestro embajador ante la OEA depositó el instrumento de ratificación en la Secretaría de esa Organización y, en vista de que el Protocolo había entrado en vigor un año y medio antes, el 16 de noviembre de 1988, en virtud de haber sido ratificado por dos tercios de los miembros de la OEA, nuestro representante tuvo que limitarse a decir que "Adicionalmente, como nota marginal, me permito manifestar, que la Función Legislativa de mi país ... interpreta...". Lo que quería decir el embajador era que, por su inoportunidad, la interpretación del Congreso Nacional era, a la vez, vacua e inconsecuente. ${ }^{4}$

Es evidente que, entre las "cuestiones de trascendental importancia para el país" respecto de las cuales la Constitución autoriza la convocatoria a una consulta popular Título IV, Capítulo 2, Sección primera- podría inscribirse un tema de política internacional. En el caso de un tratado, el llamado a consulta no significaría, en los casos en que se requiera de aprobación parlamentaria, la eliminación de la consideración legislativa. (En el hecho, la Constitución del año 1979 autorizaba en esos casos, hasta que fue reformada en este contexto, la convocatoria a consulta solamente si el tratado había sido rechazado por el Congreso). Aunque se habló de la posibilidad de convocar una consulta con respecto a los acuerdos de paz con el Perú, dicha medida constitucional no se ha invocado hasta el momento pero es muy frecuente en otros países cuando los gobiernos consideran la convocatoria a consulta, plebiscito o referéndum como un recurso útil para conseguir el respaldo de la ciudadanía a una decisión delicada o polémica de política exterior. En otros casos es una manera de promover la aprobación parlamentaria.

Nuestra actual Constitución contiene otras disposiciones que pueden tener relación con la política exterior o afectar las atribuciones del presidente de la República en esa materia. Por ejemplo, el artículo 25 prescribe que en ningún caso se concederá la extradición de un ecuatoriano, cuyo juzgamiento se sujeterá siempre a las leyes del Ecuador. Este es un principio generalmente aceptado por la comunidad internacional, pero en algunos países, como Colombia, se ha aceptado la extradición de nacionales. En los artículos 14 y 15 se dispone que los contratos celebrados por las instituciones del Estado con personas naturales o jurídicas extranjeras "llevarán implícita la renuncia a toda reclamación diplomática". Si tales contratos fueren celebrados en el Ecuador "no se podrá convenir la sujeción a una jurisdicción extraña, salvo el caso de convenios internacionales". Las personas naturales o jurídicas extranjeras no podrán adquirir tierras o concesiones en "zonas de seguridad nacional."s

Aunque la reciente controversia en el Congreso Nacional sobre la interpretación de una disposición "novedosa" incluida en la actual Constitución torna riesgosa toda sugerencia de enmienda o adición, es evidente que el texto que nos rige se beneficiaría de algunas modificaciones de texto y de fondo. Siempre es conveniente que juristas conocedores del derecho internacional intervengan en la redacción de las disposiciones que regulan los temas de política exterior, y es evidente que la Asamblea Constituyente no procedió en esa forma. Otros cambios, como la inclusión de disposiciones sobre la adhesión del Ecuador a tratados multilaterales abiertos, se hacen necesarios para ponernos al día con normas y prácticas de la diplomacia moderna.

Pero más allá de esas posibles modificaciones, nuestro país debe superar un problema lamentable que puede causarle enormes perjuicios en sus relaciones internacionales: tenemos un marco jurídico deficiente que afecta negativamente nuestra credibilidad internacional y no inspira confianza a los inversionistas extranjeros. Para que el Ecuador alcance un mayor crecimiento de su economía - que es la única forma de reducir la pobreza- debe promover mayores niveles de inversión y de cooperación internacional. Sin estabilidad política, institucional y jurídica no se puede desarrollar una acción internacional eficaz con ese propósito. Las reformas constitucionales que deberían hacerse para construir en nuestro país un esquema de seguridad jurídica que realmente permita al Ecuador adaptarse a las nuevas circunstancias del mundo podría ser el tema de una profunda, y probablemente fecunda, reflexión académica. 
NOTAS

1. Después de haber debatido largamente -durante más de ocho años- sobre todas las materias que se consideraron pertinentes, la Asamblea General de las Naciones Unidas adoptó en 1970 la Declaración sobre los principios de derecho internacional referentes a las relaciones de amistad y a la cooperación entre los Estados de conformidad con la Carta de las Naciones Unidas.

2. Como consecuencia de la decisión del Congreso, se sometió a aprobación parlamentaria solamente el Acuerdo Amplio Ecuatoriano-Peruano de Integración Fronteriza, Desarrollo y Vecindad suscrito en Brasilia. Hay quienes sostienen que debió someterse al Congreso el acuerdo sobre fijación de la frontera que figura en el Acta Presidencial de Brasilia aunque prevaleció el criterio de que ese acuerdo fundamentalmente tiene el propósito de dar ejecución total y definitiva del Protocolo de Río de Janeiro.

3. Ministerio Secretaría de Estado de Relaciones Exteriores, Informe a la Nación, 1998-1999, Tomo I, p.23

4. El Congreso, en su resolución de aprobación del Protocolo de Cartagena de Indias había resuelto dejar constancia de que la expresión "la victoria no da derechos" que aparece en el literal f) del Artículo 3 del Protocolo- debía interpretarse en el sentido de que "la victoria no crea derechos", en armonía con una tesis permanente del Ecuador en esa materia, la llamada Doctrina Sucre. El texto de la resolución de aprobación del Protocolo de Reformas de la OEA fue publicado en el Registro Oficial número 384 (Año II), del viernes 23 de febrero de 1990, y el texto del Protocolo fue publicado en el Registro Oficial número 391 (Año II), del jueves 8 de marzo de 1990.

5. A principios de los años noventa el Gobierno de Colombia protestó porque nuestra Ley de Seguridad Nacional había definido la zona de seguridad nacional como una "faja de 50 kilómetros medida hacia el interior de la línea de frontera..." Esa disposición se suprimió recientemente de acuerdo con la Ley de Promoción de las Inversiones, también llamada Trole II. 